\title{
Tobacco Use and Oral Cancer: A Global Perspective
}

\author{
Newell Johnson, BDSc, MDSc, Ph.D.
}

Abstract: For both genders, cancer of the mouth and pharynx ranks sixth overall in the world; it is also the third most common site among males in developing countries. In industrialized countries, men are affected two to three times as often as women, largely due to higher use of alcohol and tobacco. Ethnicity strongly influences prevalence due to social and cultural practices, as well as socioeconomic differences. In population terms, survival rates around the world show little improvement. In terms of etiology, the effects of tobacco use, heavy alcohol consumption, and poor diet together explain over 90 percent of cases of head and neck cancer. All forms of tobacco represent risk factors for oral cancer, but on present evidence, snuff habits as they exist in Scandinavia and probably in the United States carry lower risks of serious health hazards, including oral cancer. Alcohol synergizes with tobacco as a risk factor for all upper aerodigestive tract SCC: this is super-multiplicative for the mouth, additive for the larynx, and between additive and multiplicative for the esophagus. The increase in oral cancer in the Western world has been related to rising alcohol use.

Dr. Johnson is Professor with the Division of Oral Medicine, Pathology, Microbiology, and Immunology, King's College School of Medicine and Dentistry in London. Direct correspondence and requests for reprints to him at Division of Oral Medicine, Pathology, Microbiology, and Immunology, King's College School of Medicine and Dentistry, Caldecot Road, London SE5 9RW, England; 44-0-207-346-3608 phone; 44-0-207-346-3624 fax; Newell.Johnson@mail.kcl.ac.uk e-mail.

Key words: epidemiology, etiology, oral and pharyngeal cancer, tobacco, alcohol, diet

$\mathrm{M}$ ost malignancies of the upper aerodigestive tract are squamous cell carcinomas (SCC) arising in the mucous membranes of the mouth, pharynx, and larynx and share common risk factors. Of all oropharyngeal malignancies reported to the SEER registries in the United States between 1973 and 1987, apart from lesions of salivary glands, gingivae, nasopharynx, nasal cavity, and sinuses, more than 95 percent were SCC. ${ }^{1}$ Neoplasms of the major salivary glands have quite distinct natural histories and ill-understood etiologies compared to mucosal cancers. Similarly naso-pharyngeal malignancies are usually Epstein Barr virus-related carcinomas (NPC), distinctly different from the more widespread alcohol- and tobacco-related SCCs of the upper aerodigestive tract. Many datasets make a distinction between lip and intraoral cancer, and we have to be clear whether "oral cancer" is taken to include oropharynx and hypopharynx. Fortunately, data for the larynx are usually recorded separately.

For both genders combined, cancer of the mouth and pharynx ranks sixth overall in the world, behind lung, stomach, breast, colon and rectum, and cervix plus corpus uteri. Mouth and pharynx are the third most common site among males in developing countries and fourth among females. The highest rates in the world for oral cancer are found in France, the Indian subcontinent, Brazil, and central/eastern
Europe. In the United States in 1997 there were 20,900 new cases and 5,600 estimated deaths among males; for females there were 9,850 new cases and 2,840 deaths. This represents a death-registration ratio of 0.274. In other words, even in an advanced society like the United States, nearly one in three people with oral cancer in time die with or as a result of their disease.

Incidence increases with age in all countries. In the West, 98 percent of oral and pharyngeal cases are in patients over forty years of age. In high-prevalence areas, cases occur prior to the age of thirtyfive due to heavy abuse of various forms of tobacco. Furthermore, a number of cases of oral mucosal SCC occur in both young and old patients often in the absence of traditional alcohol and tobacco risk factors and may pursue a particularly aggressive course. ${ }^{2}$

In industrialized countries, men are affected two to three times as often as women, largely due to their higher indulgence of alcohol and tobacco for intra-oral and laryngeal cancer and higher exposure to sunlight for lip cancer among those who work outdoors. However, the incidence of tongue and other intra-oral cancer for women can be greater than or equal to that for men in high incidence areas such as India, where chewing and sometimes smoking are also common among women. In the United States the annual death rate per 100,000 population in 1991- 
93 for oral and pharyngeal cancer was 4.4 for males and 1.6 for females, down from 5.9 and 1.9 respectively in 1971-73. Note, however, that because the U.S. population has become larger and older, actual numbers of deaths have risen over the past twentyfive years, more so in women.

Ethnicity strongly influences prevalence due to social and cultural practices, as well as death rates due to socioeconomic differences. Where these represent risk factors, their continuation by emigrants from high-incidence regions to other parts of the world results in comparatively high rates in immigrant communities. Among Indians in the Malay Peninsular, for example, oral cancer has long been considerably more common than among Malays or Chinese. ${ }^{3}$ Similar trends are noted among Indian migrants from India to Natal. ${ }^{4}$ In the United States both the incidence and mortality rates for alcoholand tobacco-related cancers in African-Americans are substantially higher than for whites. African-Americans are not enjoying the same downward trends in mortality rates, and the incidence for males is so high, at 20.4 per 100,000 per annum, that oral/pharyngeal cancer becomes the fourth most common site for malignant disease.

There is much geographical variation regarding mortality rates, with several European countries, France, Hungary, and the Czech Republic ranking especially high. This pattern has historically been linked to heavy alcohol and tobacco use in these communities; see the article by Dr. Banoczy in this issiue for further data.

Mortality rates show major changes over time. Recently the SEER program reported an overall fall in the mortality rate of oral cancer between 1973 and 1993 of 22.6 percent (Table 1). However, there is a considerable rise in mortality among African-American males (10.3 percent), more so in those aged sixty- five and over (16.4 percent), an even larger rise in older African-American females (19.1 percent), and a smaller but significant rise among older white females (3.4 percent). Furthermore, for males of all races there is a decline in five-year survival rates from 53.5 percent in 1974 to 47.5 percent in 1988: rates range from a high of 72.1 percent for white females in Utah to a low of 24.8 percent for black males in metropolitan Atlanta. These are striking differences likely to be explained by socioeconomic condition, age, stage at diagnosis, continued presence or absence of environmental risk factors, and access to hospital and community care.

Within the continental United States, there is a greater than fivefold regional variation by state in mortality rates due to ethnic differences, socioeconomic status, and differences in risk factors, including the use of oral smokeless tobacco in the South. Striking variations are also seen across the European Union (EU). ${ }^{6}$ There is likely to be a doubling in deaths from oral cancer in the EU between 1970 and 2020, fueled by younger age groups and therefore continuing well into the next century. The highest mortality rates in the world for laryngeal cancer in men are in Hungary, Poland, Slovakia, and Romania. ${ }^{7}$

In population terms, survival rates around the world show little improvement. Cure and survival rates are better in highly specialized, high-volume treatment institutions. But such expert management is not uniformly available. The major determinants of survival, discussed elsewhere, ${ }^{8}$ include:

- Patient factors at diagnosis: age, gender, socioeconomic status, nutritional status, intercurrent disease, and continuing presence of risk factors ${ }^{9}$

- Tumor factors: site, size, differentiation, and biological behavior of the neoplasm, including host immune response, extent of regional, and distant metastases

Table 1. Mortality trends for oral and pharyngeal cancer in the United States between 1973 and 1993, by race and sex ${ }^{5}$

\begin{tabular}{|c|c|c|c|c|c|c|c|c|c|}
\hline & & All race & & & Whites & & & Blacks & \\
\hline & Total & Males & Females & Total & Males & Females & Total & Males & Females \\
\hline All ages & & & & & & & & & \\
\hline Percent change & -22.6 & -26.2 & -16.3 & -26.7 & -31.6 & -17.5 & 2.9 & 10.3 & -8.8 \\
\hline Est. ann percent & $-1.4^{*}$ & $-1.7^{*}$ & $-1.0^{*}$ & $-1.7^{*}$ & $-2.1^{*}$ & $-1.1^{*}$ & -0.1 & 0.2 & -0.3 \\
\hline Under 65 & & & & & & & & & \\
\hline Percent change & -26.7 & -24.5 & -34.0 & -33.2 & -32.3 & -37.5 & -1.6 & 7.3 & -21.5 \\
\hline Est ann percent & $-1.8^{*}$ & $-1.6^{*}$ & $-2.3^{*}$ & $-2.2^{*}$ & $-2.1^{*}$ & $-2.6^{*}$ & -0.4 & 0.0 & $-1.2^{*}$ \\
\hline 65 and over & & & & & & & & & \\
\hline Percent change & -18.2 & -26.8 & 3.7 & -20.4 & -31.1 & 3.4 & 12.6 & 16.4 & 19.1 \\
\hline Est ann percent & $-1.1^{*}$ & $-1.8^{*}$ & 0.2 & $-1.3^{*}$ & $-2.1^{*}$ & 0.1 & $0.6^{*}$ & $0.7^{*}$ & $1.4^{*}$ \\
\hline
\end{tabular}


- Management factors: treatment modality and thoroughness, with smaller components derived from the quality and extent of supportive care and after careand treatment institution facilities.

\section{Etiology and Risk Factors}

\section{Familial and Genetic Predisposition}

Lip cancer is among the sites that show the strongest cancer clustering within families in the genealogical records of the Utah (Mormon church) database; the others are leukemia, lobular breast cancer, early melanoma, and adenocarcinomas of the lung in females. ${ }^{10}$ Studies from Kerala, South India, revealed a familial association in only 0.94 percent of the total oral cancers accrued January to July 1995 , consistent with autosomal inheritance. ${ }^{11}$ In the Netherlands, Copper et al. ${ }^{12}$ took 617 first-degree relatives of 105 patients with head and neck cancer and found among them thirty-one cases of cancer of the respiratory and upper digestive tract versus ten cases in the control group composed of first-degree relatives of the index patient's spouses $(n=617)$. This produced a relative risk $(R R)$ of $3.5(p=0.0002)$ for firstdegree relatives, and of $14.6(\mathrm{p}=0.0001)$ for siblings. There was no relation to smoking and drinking histories, implying a constitutional factor affecting the way genotoxic compounds are dealt with.

It is important to control for environmental factors in such studies. This research was done in a large case/control study of oral and pharyngeal cancer in the United States. ${ }^{13}$ The strongest elevated risk was of oral/pharynx cancer among those whose sisters developed other cancers, but here the odds ratios (ORs) were only 1.6 (95 percent Confidence Interval 1.1-2.2). There are likely to be important familial clusters of individuals with more or less adequate genetic polymorphisms for carcinogen metabolising and detoxifying enzymes. Jefferies et al. ${ }^{14}$ and Llewellyn et al. ${ }^{2}$ have critically reviewed the evidence in this growing field.

\section{Occupational Risks}

Outdoor workers like farmers, fishermen, foresters, and postal delivery workers are at risk of lip cancer from ultraviolet light in two venues: first, in countries at high latitudes with clean air through which UV penetrates easily, albeit for only part of the year, such as Finland, ${ }^{15}$ and, second, in countries closer to the equator with regular long hours of sunshine, such as rural Greece, where lip can account for 60 percent of oral cancers. ${ }^{16}$ A study from California shows that the risk of lip cancer for women is strongly related to lifetime solar radiation exposure, but that lipstick and other sunscreens are protective. ${ }^{17}$ Well-differentiated SCCs arise out of long-standing solar keratoses.

The effects of early life exposure are longstanding. New Zealanders, for example, have four or more times the RR of developing cutaneous melanoma and lip cancer than of residents of England and Wales, while migrants in both directions retain intermediate risks. ${ }^{18}$

Part of the urban/rural difference in incidence of head and neck cancer also relates to atmospheric pollution. Mean sulphur dioxide and smoke concentrations in the atmosphere are positively correlated with SCC of the larynx and, to a lesser extent, the pharynx in parts of England. ${ }^{19}$ The importance of fossil fuel combustion at work is confirmed in a large study in four areas in the United States (1,114 cases, 1,268 controls), with ORs of approximately 2.0 for pharyngeal sites. ${ }^{20}$ Asbestos, pesticide exposures, and mists from strong inorganic acids (OR 95 percent $\mathrm{CI}$ 1.1-2.9 for the latter) were shown for laryngeal cancer in Uruguay. ${ }^{21}$ The risk of laryngeal cancer from acid mists in the steel industry is confirmed in a United States study of 1,031 exposed men. ${ }^{22}$

\section{Tobacco Use}

Taken together, the effects of tobacco use, heavy alcohol consumption, and poor diet probably explain over 90 percent of cases of head and neck cancer. Among men in industrialized countries, smoking is estimated to be the cause of 40-45 percent of all cancer deaths, 90-95 percent of lung cancer deaths, over 85 percent of oral cancer deaths, 75 percent of chronic obstructive lung disease deaths, and 35 percent of cardiovascular disease deaths in those aged thity-five to sixty-nine years. Thus, although upper aerodigestive tract cancers are prominently represented, lung cancer and other pulmonary and cardiovascular diseases should be the starting point for antitobacco counselling. Alcohol synergizes with tobacco as a risk factor for all upper aerodigestive tract SCC: 
this is super-multiplicative for the mouth, additive for the larynx, and between additive and multiplicative for the esophagus. ${ }^{23}$

\section{Types of Tobacco Use: A Global Perspective}

Smoking of tobacco as factory-made cigarettes, cigars and cheroots, and loose tobacco in pipes or hand-made cigarettes is familiar to all. Tar, nicotine, and nitrosamine content varies greatly, depending on species, curing additives, and method of combustion. Such smoking habits are the predominant form of tobacco use in the West and among increasing millions in developing countries. With government regulation of tobacco advertising, restrictions on smoking in public transport and public places, and the awarding of damages to individuals and health authorities, manufacturers are increasingly targeting developing countries for sales, especially of their higher tar varieties.

\section{Smokeless Tobacco}

Much of the tobacco in the world is consumed without combustion. Rather, it is placed in contact with mucous membranes, through which nicotine is absorbed to provide the pharmacological effect. Use of nasal stuff, popular in the last century, is returning. Other forms of snuff, loose or packeted and placed in the oral vestibule, are common in Scandinavia and the United States. Tobacco is also prepared in blocks or flakes for chewing. In developing countries, tobacco is mostly consumed mixed with other ingredients (Table 2 ). The very extensive evidence for carcinogenicity of these mixtures is covered exhaustively in Daftary et al. ${ }^{24}$ and Gupta et al. ${ }^{25}$ Toombak, the form used in Sudan, contains very high levels of tobacco specific nitrosamines (TSNs), and users show significantly increased risks of oral squamous cell carcinoma. ${ }^{26}$

\section{Betel Quids}

The recommended terminology is that of Zain et al. ${ }^{27}$ Quids are prepared from areca nut, cured or sun-dried, and chopped, then usually placed on a leaf of the Piper betel vine, although the influorescence is used by some, for example, in Papua New Guinea. Slaked lime is an essential ingredient. It lowers $\mathrm{pH}$ and accelerates release of alkaloids from both tobacco and nut, with enhanced pharmacological effect. Daftary et al. ${ }^{28}$ set out the evidence for the carcinogenicity of betel quid and the important role of tobacco in considerable detail.

\section{Areca Nut Alone}

Although the $\mathrm{IARC}^{29}$ concluded that there was insufficient evidence that the chewing of betel quid without tobacco was carcinogenic to man, this is a probability. Areca nut is certainly the main aetiological agent in oral submucous fibrosis, ${ }^{30}$ but in this case-control study twelve of the fourteen concurrent oral cancer and submucous fibrosis patients also used tobacco.

In Guam, where areca nut is chewed alone or with leaf only, there is apparently no increase in oral cancer. ${ }^{31}$ Conversely in Taiwan, most heavy chewers of betel quids do not include tobacco, yet oral can-

Table 2. Some common forms of oral smokeless tobacco

\begin{tabular}{lll} 
Habit & \multicolumn{1}{c}{ Ingredients } & \multicolumn{1}{c}{ Population } \\
\hline Pan/paan/betel quid & Areca nut, betel leaf/inflorescence, slaked lime, \\
catechu, condiments, with or without tobacco & Indian subcontinent, Southeast Asia, \\
Khaini & Pobacco and lime & Bihar (India) \\
Mishri & Burned tobacco & Maharashtra (India) \\
Zarda & Boiled tobacco & India and Arab countries \\
Gadakhu & Tobacco and molasses & Central India \\
Mawa & Tobacco, lime and areca & Bhavnagar (India) \\
Nass & Tobacco, ash, cotton or sesame oil & Central Asia, Iran, Afghanistan, Pakistan \\
Naswar/niswar & Tobacco, lime, indigo, cardamom, oil, menthol, etc. & Central Asia, Iran, Afghanistan, Pakistan \\
Shammah & Tobacco, ash, and lime & Saudi Arabia \\
Toombak & Tobacco and sodium bicarbonate & Sudan
\end{tabular}


cer is clearly associated. ${ }^{32}$ Importantly, the synergistic role of alcohol has not been evaluated in these studies. ${ }^{33}$ As we evaluate the dangers of these complex mixtures, it is important to remember that betel leaf is protective, ${ }^{34}$ and at least two compounds have been identified: carotene and hyroxychavicol, an astringent antiseptic.

\section{Oral Snuff in Scandinavia and North America}

Brown et al. ${ }^{35}$ described "snuff-dipper's cancer" in the southeastern United States due to the habit of placing snuff in the labial sulcus - the basis of the classic description of verrucous carcinoma by Ackermann, ${ }^{36}$ confirmed later by $\mathrm{McCoy}$ and Waldron. ${ }^{37}$ Females in the textile industry in this area have a high prevalence of snuff dipping and elevated death rates from oral cancer. ${ }^{38}$

There is also concern regarding use of factoryproduced portion-packed snuff and the oral cancers it might cause, particularly among adolescents in the United States. ${ }^{39}$ The U.S. Department of Health and Human Services ${ }^{40}$ concluded that such use constituted a significant risk to health from oral cancer and other oral lesions and that it could lead to nicotine addiction and dependence. Congress banned the advertising of smokeless tobacco on radio and television in 1986 and required health warnings on packages and printed advertisements. The EU banned the sale of portion and loose snuff in all of its member states in 1992: when Sweden joined the EU in 1995, it was exempted from the ban on sales, but exports were banned..$^{41}$ The IARC ${ }^{29}$ stated that there was sufficient evidence that snuff causes cancer, and the Swedish government requires warning labels on such products.

Hatsukami and Severson ${ }^{42}$ comprehensively reviewed the North American scene (see also the article by Dr. Winn in this issue). This habit is addictive and can produce hyperkeratotic lesions in the area of habitual contact. ${ }^{43}$ Overall, there is limited evidence that malignancies follow, though there may be a long latent period. A paper ${ }^{44}$ based on combined data of the 1986 U.S. National Mortality Followback Survey $(n=16,598)$ and the coincident National Health Interview Survey (1987), with correction for confounders, concluded that use of smokeless tobacco, either as snuff or chewing tobacco, does not increase the risk of oral or other digestive cancers. There is a considerable margin for error here, how- ever, as the number of users of oral smokeless tobacco was small and the assessment of use was both reliant on individual recollection and grouped into large and insensitive categories. Importantly, alcohol emerged as a major risk factor for oral cancer with a strong dose-response relationship, as it did to a lesser extent with other digestive cancers. Smoking was associated with risk of oral but not other digestive cancers. Bouquot and Meckstroth ${ }^{45}$ have pointed out that West Virginia, a state with the highest consumption of chewing tobacco in the United States, has below average oral cancer incidence rates. Chewing tobaccos are distinctly different from snuff, and snuff as manufactured and used in Europe and North America is very different from snuff-like products used in the Middle East, which are made locally in a variety of small-scale industries, by individual vendors, or directly by the users. In Scandinavia it is clear that local snuff is not a major risk factor: two recent case-control studies of oral cancer cases in Sweden have failed to show an association. ${ }^{46}$ This is because Swedish snus is not fermented and contains much lower nitrosamine levels than fermented tobaccos.

The view that smokeless tobacco use may be associated with a lower risk of oral cancer in the United States has led to a movement to advocate the practice as a less dangerous alternative to smoking and an aid to nicotine withdrawal in those addicted to smoking. ${ }^{47,48}$ This approach has been condemned on the grounds that it can lead to nicotine addiction and it ignores both the potential role of snuff in other cancers and cardiovascular diseases and the fact that other ethically accepted forms of nicotine replacement therapy (such as chewing gums, skin patches, inhalators, and nasal sprays) are widely available. It is of interest, therefore, to consider two recent Swedish studies: one showed a RR for myocardial infarcation of 0.89 ( 95 percent CI 0.62-1.29) in snuff users, compared to 1.87 (95 percent CI 1.40-2.48) in smokers. ${ }^{49}$ Another study from health screenings of 135,036 construction workers showed that the RR for death due to cardiovascular disease was 1.4 (1.21.6) for this group, compared to 1.9 (1.7-2.2) for smokers. ${ }^{50}$ No increased risk among snuff users who had never smoked was found among men with Crohn's disease and ulcerative colitis in a case-control study ${ }^{51}$ The possibility of increased risk of cancer at other sites has not yet been fully addressed. Nevertheless, on present evidence, snuff habits as they exist in Scandinavia and, probably in the United 
States, carry low risks of serious health hazards, including oral cancer. As Axell ${ }^{52,53}$ points out, however, this does not mean that oral snuff should be encouraged: it almost always produces mucosal lesions, often affects salivary flow, causes gingival recession, and creates nicotine dependence and addiction.

\section{Smoking and Head and Neck Cancer}

The most comprehensive source of evidence for the carcinogenicity of tobacco smoke remains the IARC publication of $1986 .{ }^{54}$ This evidence is summarized by the U.S. Surgeon General's Report of 1989: upper aerodigestive sites have the highest ARs in males, of all the many sites influenced by smoking. A major difficulty in accurately quantifying smoking risks for aerodigestive tract cancer is its strong synergism with alcohol.

Pipe smoking has long been associated with lip cancer, where the nature of the stem and its permeability and, maybe, temperature are cofactors. Some literature suggests that pipe and cigars are less risky for oral cancer than cigarettes, ${ }^{55}$ but a study from North Italy ${ }^{23}$ shows higher risks associated with these practices for cancer of the mouth and esophagus than cigarettes.

The relationship between smokine and the anatomical site of oral cancer is less clear-cut than with smokeless tobacco. Pooling of carcinogens in saliva gives cancers in the "gutter" area-floor of the mouth and ventral and lateral tongue. Mashberg and Meyers $^{56}$ reported in a U.S. population that 201 of 207 asymptomatic, primarily erythroplastic carcinomas were in three locations: floor of mouth (101 carcinomas), ventral or lateral tongue (36 carcinomas), and soft palate (64 carcinomas). In the Amsterdam series,${ }^{57}$ the floor of mouth and retromolar area were significantly more related to tobacco use than cancers or the tongue and cheek. However, in another series of 359 male cases among U.S. veterans, smoking was more strongly associated with soft palate cancers than anterior sites, and alcohol was associated with floor of mouth lesions. ${ }^{58}$ This is interesting because the long-recognized lesions of stomatitis nicotina ("smokers palate") have a low malignant potential (except in reverse smokers). These predominantly affect the hard palate, producing hyperkeratosis without significant epithelial dysplasia, with plugging of the orifices of minor salivary glands and associated inflammation. Stomatitis nicotina, in the
West, is most commonly associated with pipe smoking, and both hard and soft palate are relatively uncommon sites of oral cancer.

\section{The Mechanisms of Tobacco Carcinogenesis}

More than 300 carcinogens have been identified in tobacco smoke or in its water-soluble components that will leach into saliva. ${ }^{54}$ The major and most studied of these are the aromatic hydrocarbon benz-pyrene and the tobacco specific nitrosamines (TSNs), nitroso-nor-nicotine (NNN), nitrosopyrrollidine (NPYR), nitrosodimethylamine (NDMA), and 4-(methylnitrosamino)-1-(3-pyridyl)1-butanone (NNK).

We have known since the 1920s that polycyclic aromatic hydrocarbons were the carcinogens present in tars, thus the interest in "low-tar" smoking materials. Benz-pyrene is a powerful carcinogen, with twenty to forty nanograms per cigarette. ${ }^{59}$ Hoffman and $\mathrm{Hecht}^{60}$ reviewed the role of N-nitrosamines. Mainstream cigarette smoke can contain NNN and NNK. These are generated primarily during pyrolysis, but also endogenously from some smokeless tobacco. They act locally, on keratinocyte stem cells, and are absorbed and act in many other tissues in the body. They produce DNA adducts, principally 06 methyl Guanine, which interfere with DNA replication. There is damage to all replicating cells, including those of the immune response.

Metabolism of these carcinogens usually involves oxygenation by $\mathrm{p} 450$ enzymes in cytochromes, and then conjugation, in which the enzyme glutathione S transferase (GST) is involved. Polymorphisms of the p450 and GST genes are currently under active study in the search for genetic markers of susceptibility to head and neck cancer, and indeed to tobacco-related cancers at many other body sites. ${ }^{61}$ Not all results are consistent, however.

\section{Marijuana Use and Head and Neck Cancer}

Reports of aerodigestive tract cancer in marijuana users have been reviewed. ${ }^{62}$ Recreational users of marijuana often also enjoy alcohol and tobacco, and tobacco usually forms part of the marijuana smoking mix. It is thus impossible at present to discern an independent risk for the smoking of cannabis 
products themselves though, because of their composition, a theoretical risk certainly exists.

Little evidence exists regarding the risk of marijuana smoking for the development of potentially malignant oral lesions. However, as with more conventional tobacco smokers, leukoedema, nicotinic stomatitis, denture-related stomatitis, angular cheilitis, and median rhomboid glossitis are more common. ${ }^{62}$

\section{Alcohol and Head and Neck Cancer}

Pure ethanol has never been shown to be carcinogenic in vitro or in animal studies. ${ }^{64} \mathrm{It}$ is presumed to act in concert with other, more direct, carcinogens in the beverage-so-called congeners - and with other environmental carcinogens, especially from tobacco. Nevertheless, an increased risk of upper aerodigestive tract cancer associated with alcohol drinking in nonsmokers has been demonstrated ${ }^{65}$

The increase in oral cancer in the Western world has been related to rising alcohol use. In England and Wales, alcohol consumption per capita fell from the turn of the century to the $1930 \mathrm{~s}$, but has more than doubled since. Using mortality from liver cirrhosis as a surrogate measure of damage to health from alcohol, Hindle ${ }^{66}$ has plotted trends over this

\begin{tabular}{|c|c|c|}
\hline & $\begin{array}{l}\text { Oral cavity } \\
(\mathrm{n}=157)\end{array}$ & $\begin{array}{l}\text { Pharynx } \\
(n=134)\end{array}$ \\
\hline \multicolumn{3}{|l|}{ WINE (drinks/week) } \\
\hline$<=20$ & 1 & 1 \\
\hline $21-34$ & $1.1\left(0.5-2.3^{*}\right)$ & $0.7(0.3-1.6)$ \\
\hline $35-55$ & $1.9(0.9-3.7)$ & $1.9(0.9-3.7)$ \\
\hline $56-83$ & $4.9(2.6-9.5)$ & $3.1(1.6-6.1)$ \\
\hline $\begin{array}{l}\text { 84+ } \\
\text { BEER (drinks/week) }\end{array}$ & $8.5(3.6-20.2)$ & $10.9(4.7-25.3)$ \\
\hline 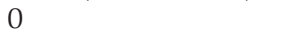 & 1 & 1 \\
\hline 1.13 & $1.0(0.6-1.8)$ & $0.5(0.3-1.0)$ \\
\hline $\begin{array}{l}\text { 14+ } \\
\text { SPIRITS (drinks/week) }\end{array}$ & $0.8(0.5-1.4)$ & $0.9(0.5-1.5)$ \\
\hline 0 & 1 & 1 \\
\hline $1-6$ & $0.7(0.4-1.3)$ & $0.4(0.2-0.9)$ \\
\hline $\begin{array}{l}7+ \\
\text { TOTAL (drinks/week) }\end{array}$ & $0.9(0.6-1.3)$ & $1.2(0.8-1.8)$ \\
\hline$<=19$ & 1 & 1 \\
\hline $20-34$ & $1.1(0.5-2.5)$ & $0.9(0.4-2.0)$ \\
\hline $35-59$ & $3.2(1.6-6.2)$ & $1.5(0.8-3.1)$ \\
\hline $\begin{array}{l}60+ \\
*(95 \text { percent confidenc }\end{array}$ & $\begin{array}{l}3.4(1.7-7.1) \\
\text { e intervals) }\end{array}$ & $3.6(1.8-7.2)$ \\
\hline
\end{tabular}

century and shown how they closely match the trends in oral cancer mortality. Taking deaths from lung cancer as a measure of tobacco damage, it is striking how the trends for oral cancer move, both down and up this century, in opposite directions: strong circumstantial evidence that alcohol rather than tobacco is the major factor in the observed trends in oral cancer mortality and, by inference, incidence.

All forms of alcoholic drink are dangerous if heavily consumed, the most dangerous reflecting the predominant habit in the population under study. Thus there is evidence for the role of beer, ${ }^{67,68}$ wine, ${ }^{69,23}$ and spirits ${ }^{70}$ which some ${ }^{71}$ have taken to implicate ethanol itself. Good evidence for the very significant role of alcohol comes from Northern Italy (Table $3)$. It is notable that the 95 percent confidence intervals for the odds ratio for all beverages do not cross unity until the total consumption is really quite highabove fifty-five drinks per week. This is consistent with other data. ${ }^{72}$ When the tobacco effect is adjusted for, heavy alcohol consumption itself produces considerable risks, with ORs or RRs of 17, 23, 33, and 70 appearing for oral cancer in the different studies. For these high rates of alcohol use/abuse, the risks are greater than for tobacco, adjusted for alcohol. Self-reported alcohol consumption tends to be underestimated, implying that alcohol may be even more important.

Alcohol is also high in calories, which suppresses appetite. Those with a serious drinking problem become socially fractured, and many choose to spend available cash on drink rather than food. All of this contributes to inadequate diet. Metabolism is further damaged by liver disease. As a result, nutritional deficiencies are common. ${ }^{74}$

\section{Risk of Oral Cancer from Mouthwash}

Winn et al. ${ }^{75}$ found increased risks associated with regular use of mouthwash, of 40 percent for men and 60 percent for women, after adjusting for alcohol drinking and tobacco use. Risks generally increased in proportion to frequency and duration of mouthwash use, and were only apparent when the alcohol content of the mouthwash exceeded 25 percent. Several published reviews ${ }^{76-77}$ have helped the British, Canadian, and American dental associations to endorse products of this type for control of dental plaque and gingivitis. 


\section{Head and Neck Cancer in Non-Users of Tobacco and/or Alcohol}

A minority of patients develop a cancer in the apparent absence of one or both of these risk factors. Rich and Radden ${ }^{78}$ found that Australian patients with oral cancer who had never used tobacco or alcohol developed their carcinomas particularly on the buccal mucosa and upper alveolar ridge; the Amsterdam data $^{57}$ are consistent with this finding. Hodge et al., ${ }^{79}$ in a Kentucky population, described thirty-three of 945 cases (3.4 percent) of head and neck cancers in non-users of tobacco. The non-users of both tobacco and alcohol had a definite majority of women, especially older women, and comparatively few cancers of the floor of the mouth. Other findings ${ }^{80}$ with oral cancer in non-user American cohorts are:

- a low incidence of second primaries,

- a higher level of differentiation of the primary lesions,

- a lower frequency of associated oral candidiasis, and

- importantly; no better overall survival.

None of these studies on the rare cases that occur in non-users of tobacco and/or alcohol dilutes the evidence that these are far and away the major risk factors. Viral infections and nutritional inadequacies, which are addressed next, are the main hypothetical factors in this group of patients.

\section{Viruses and Head and Neck Cancer}

About 15 percent of all human cancers may have an etiological relationship to viruses.

\section{Papilloma Viruses}

HPV 16 is the most common type associated with cervical and oral cancers. ${ }^{81}$ In vitro studies show that primary human oral epithelial cells can be immortalized by high-risk HPV types. ${ }^{82,83}$ However, exposure to tobacco-related chemicals was required for these cells to progress to a fully malignant phonotype. ${ }^{84}$
That infection with high-risk HPV, and even demonstrable integration of known viral oncogenes, is neither necessary nor sufficient for the development of head and neck cancer is supported by our observations that $\mathrm{p} 53$ mutations (but not over-expression) correlate with the absence of HPV $16 \mathrm{E} 6 .^{85}$ This finding is consistent with data from Riethdorf et al., ${ }^{86}$ who showed that only about 40 percent of head and neck squamous carcinomas carrying p 53 mutations also carried high-risk HPV, and only about 40 percent of HPV positive tumours showed p53 mutations.

The question of the predictive value of HPV infection in at-risk individuals with or without a detectable potentially malignant lesion is important. High-risk HPVs have frequently been detected in benign oral lesions and in clinically and histologically normal mucosa. ${ }^{87,88}$ Whether or not detecting them adds to the utility of oral screening is unknown and requires substantial further work.

\section{Herpes Simplex Viruses}

Animal studies show that HSV can act as a cocarcinogen with tobacco or other chemical carcinogens $^{89}$ and that immunization against HSV can inhibit the co-carcinogenic effect with dimethyl benzanthracene. ${ }^{90}$

Serum IgA antibodies to HSV I are higher in smokers and higher again in smokers with head and neck cancers, suggesting that prolonged exposure to HSV may sensitize the mucosa to tobacco carcinogens. A more likely explanation, however, is that the generalized immunosuppression, particularly of natural killer-cell (NK) activity, which is induced by smoking favors the acquisition or chronicity of HSV infections/carriage, with consequent raised antibody titres. ${ }^{91}$

\section{Fungal Infections}

A proportion of leukoplakias are superficially invaded by fungal hyphae, ${ }^{92}$ particularly nodular leukoplakias, and these have a higher risk of malignant transformation. There is also a clear association between smoking and the risk of candidal infection in the mouth ${ }^{93}$ : this also applies to HIV positive individuals, compounding the risk. ${ }^{94}$ Patients with iron deficiency, clearly at increased risk for oral cancer, are also more prone to oral candidiasis, indicat- 
ing an interactive, multifactorial process in oral carcinogenesis.

It remains uncertain as to whether candida invades oral potentially malignant lesions as a secondary event or it is causal in the lesion and/or subsequent cancer. However, a mechanism clearly exists, as these organisms have the necessary enzymes to promote the nitrosation of dietary substrates. ${ }^{95}$

\section{Diet and Nutrition in the Etiology of Oral Cancer}

Interest here relates to the roles of iron, of the anti-oxidant or free-radical scavenging vitamins A, $\mathrm{C}$, and $\mathrm{E}$ and to trace elements such as Zinc and Selenium, for which there is evidence of a protective effect. There is a high incidence of upper gastro-intestinal tract cancer in middle-aged women with chronic anaemia, with dysphagia, glossitis, and atrophy of associated mucosae - the Plummer-Vinson or Patterson-Brown-Kelly syndrome. In animals rendered experimentally iron-deficient by venesection and a low iron diet, there is epithelial atrophy ${ }^{96}$ and increased cancer risk, clearly shown when such animals are challenged with chemical carcinogens. ${ }^{97}$

\section{Food Groups}

Of thirteen case-control studies that have examined the association between fruit and vegetable consumption and oral/pharyngeal cancer, eleven report a meaningful inverse association..$^{98-100}$ The reduction in risk with fruits, from the highest to the lowest intake, varies from 80 percent to 20 percent $^{101}$ and is evident for tongue, mouth, and pharynx. ${ }^{102}$ There is similar protection from vegetables rich in carotenes. ${ }^{23,103,104} \mathrm{~A}$ strong protective effect is evident for carotenoids and vitamin $\mathrm{C}$ from vegetables and fruit and of fiber intake in oral cancer risk in an important study in Beijing, China. ${ }^{105}$

La Vecchia et al. ${ }^{98}$ estimate that approximately 15 percent of oral and pharyngeal cancers in Europe can be attributed to dietary deficiencies or imbalances, perhaps accounting for 5,000 avoidable deaths per year. Similar conclusions can be drawn from studies of laryngeal cancer. ${ }^{106}$ In the presence of tobacco and/or alcohol, low intake of fruit and vegetables has been estimated to account for 25-50 percent of cases among men. ${ }^{107}$

\section{Dental Factors in the Etiology of Head and Neck Cancer}

Clinicians have long noticed an association between poor oral hygiene, poor dental status, and oral cancer; in addition, "dentition" (recorded as number of natural teeth, appliances, sharp or fractured teeth) appears as a correlate in several studies. ${ }^{70}$ As these are certain to be confounded by socioeconomic, tobacco, alcohol abuse, nutritional, and other correlates of cancer risk, it requires carefully designed and large case series and case control studies to evaluate the importance of dental factors. Furthermore, it is well known that, in chemical carcinogenesis experiments in animals, repeated traumatizing of mucosa localizes the site at which the tumor appears, increases the yield, and reduces the latent period. Many human cases are described of an oral cancer at the site of chronic trauma arising from a broken tooth, a denture clasp, or an ill-fitting denture flange or excrescence.

Three recent studies indicate that denture wearing per se is not a risk factor, but that chronic ulceration from an unsatisfactory appliance may promote a neoplasm in the presence of other risk factors. ${ }^{108}$ Data from a northern Sweden study ${ }^{46}$ and from a smaller study in the United States ${ }^{109}$ show no increased risk associated with fillings, dentures, or fixed prostheses nor, importantly, in the Swedish study, with experience of dental x-rays.

\section{REFERENCES}

1. Muir C, Welland L. Upper aerodigestive tract cancers. Cancer 1995;75(1)Suppl:147-53.

2. Llewellyn CD, Johnson NW, Warnakulasuriya KAAS. Risk factors for squanous cell carcinoma of the oral cavity in young people: a comprehensive literature review. Oral Oncol 2000; in press.

3. Ramanathan K, Lakshmi S. Oral cancer in Chinese males. Asian J Med 1974;10:3-7.

4. van Wyck CW, Stander I, Padayachee A, Grobler-Rabie AF. The areca nut habit and oral squamous cell carcinoma in South African Indians. South African Dent J 1992;83:425-9.

5. Ries LAG, Kosary CL, Hankey BF, Harras A, Miller BA, Edwards BK (eds). SEER Cancer Statistics Review, 1973-1993: Tables and Graphs, National Cancer Institute. Bethesda, MD, 1996.

6. Smans M, Muir CS, Boyle P. Atlas of cancer mortality in the European Economic Community. Lyon: IARC Sci Publ 107, 1992. 
7. Zatonski W, Smans M, Tyczynski J, Boyle P. Atlas of cancer mortality in Central Europe. Lyon: IARC Sci Publ 1996;134:1-175.

8. Edwards D, Johnson NW. Treatment of upper aerodigestive tract cancers in the United Kingdom and its effect on survival. Br J Cancer 1999;81:323-9.

9. Macfarlane GJ, Macfarlane TV, Lowenfels AB. The influence of alcohol consumption on worldwide trends in mortality from upper aerodigestive tract cancers in males. J Epidemiol Community Health 1996a;50:636-9.

10. Canon-Albright LA, Thomas A, Goldgar DE, et al. Familiarity of cancer in Utah. Cancer Res 1994;54:237885.

11. Ankathil R, Mathew A, Joseph F, Nair MK. Is oral cancer susceptibility inherited? report of five oral cancer families. Eur J Cancer Oral Oncol 1996a;32B:63-7.

12. Copper MP, Jovanovic A, Nauta JJ, et al. Role of genetic factors in the aetiology of squamous cell carcinoma of the head and neck. Arch Otolaryngol Head Neck Surg 1995;121:157-60.

13. Goldstein AM, Blot WJ, Greenberg RS, et al. Familial risk in oral and pharyngeal cancer. Eur J Cancer Oral Oncol 1994;30B:319-22.

14. Jefferies S, Eeles R, Goldar D, et al. The role of genetic factors in predisposition to squamous cell cancer of the head and neck. Br J Cancer 1999;79:865-7.

15. Pukkala E, Notkola V. Cancer incidence among Finnish farmers 1979-93. Cancer Causes Control 1997;8:25-33.

16. Antoniades DZ, Styanidis K, Papanayatou P, Trigonidis G. Squamous cell carcinoma of the lips in a northern Greek population: evaluation of prognostic factors on five year survival rate. Eur J Cancer Oral Oncol 1995;31B:333-9.

17. Pogoda JM, Preston-Martin S. Solar radiation, lip protection and lip cancer risk in Los Angeles county women. Cancer Causes Control 1996;7:458-63.

18. Swerdlow AJ, Cooke KR, Skegg DC, Wilkinson J. Cancer incidence in England and Wales and New Zealand and in migrants between the two countries. Br J Cancer 1995;75:236-43.

19. Wake M. The urban/rural divide in head and neck cancer-the effect of atmospheric pollution. Clin Otolaryngol 1993;18:298-302.

20. Huebner WW, Schoenberg JB, Kelsey JL, et al. Oral and pharyngeal cancer and occupation: a case-control study. Epidemiology 1992;3:300-9.

21. De Stefani E, Boffeta P, Oreggia F, Ronco F, Kogevinas $\mathrm{M}$, Mendilaharsu M. Occupation and the risk of laryngeal cancer in Uruguay. Am J Ind Med 1998a;33:537-42.

22. Streenland K. Laryngeal cancer among works exposed to acid mists. Cancer Causes Control 1997;8:34-8.

23. Franceschi S, Talamani R, Barra S, et al. Smoking and drinking in relation to cancers of the oral cavity, pharynx, larynx and oesophagus in Northern Italy. Cancer Res 1990;50:6502-7.

24. Daftary DK, Murti PR, Bhonsle RB, Gupta PC, Mehta FS, Pindborg JJ. Risk factors and risk markers for oral cancer in high incidence areas of the world. In: Johnson NW, ed. Risk markers for oral diseases. Vol 1. Oral cancer. Cambridge: Cambridge University Press, 1991:29-63.
25. Gupta PC, Hamner JE, Murti PR. Control of tobaccorelated cancers and other diseases. Delhi: Oxford University Press, 1992.

26. Idris AM, Ahmed HM, Malik MAO. Toombak dipping and cancer of the oral cavity in the Sudan: a case control study. Int J Cancer 1995;63:477-80.

27. Zain RB, Gupta PC, Warnakulasuriya S, Shrestha P, Ikeda $\mathrm{N}$, Axell T. Oral lesions associated with betel quid and tobacco chewing habits. Oral Dis 1997;3:204-5.

28. Daftary DK, Murti PR, Bhonsle RB, Gupta PC, Mehta FS, Pindborg JJ. Chapters 36 and 37. In: Prabhu SR, Wilson DF, Daftary DK, Johnson NW, eds. Oral diseases in the tropics. Delhi: Oxford Medical Publications, 1992:402-48.

29. International Agency for Research on Cancer. Tobacco habits other than smoking: Betel quid and areca nut chewing, and some related nitrosamines. IARC Monogr Eval Carcinog Risk Chem Hum 37. Lyon: IARC, 1985.

30. Maher R, Lee AJ, Warnakulasuriya KAAS, Lewis JA, Johnson NW. Role of areca nut in the causation of oral submucous fibrosis: a case-control study in Pakistan. J Oral Pathol Med 1994;23:65-9.

31. Stich HF, Rosin MP, Brunnermann KD. Oral lesions, genotoxicity and nitrosamines in betel quid chewers with no obvious increase in oral cancer risk. Cancer Lett 1986;31:15-25.

32. Ko YC, Chiang TA, Chang SJ, Hsieh SF. Prevalence of betel quid chewing habit in Taiwan and related socio-demographic factors. J Oral Pathol Med 1992;21:261-4.

33. Thomas S, Kearsley J. Betel quid and oral cancer: a review. Eur J Cancer Oral Oncol 1993;29B:251-5.

34. Nagabhushan M, Amonkar AAJ, DeSouza AV. Nonmutagenicity of betel leaf and its anti-mutagenic action against environmental mutagens. Neoplasma 1987;34:159-68.

35. Brown RL, Shu JM, Scarborough JE, Wilkins SA, Smith RR. Snuff dippers intraoral cancer: clinical characteristics and response to therapy. Cancer 1965;18:2-13.

36. Ackerman LV. Verrucous carcinoma of the oral cavity. Surgery 1948;23:670-8.

37. McCoy JM, Waldron CA. Verrucous carcinoma of the oral cavity. Oral Surg Oral Med Oral Pathol 1981;52:623-9.

38. Winn DM, Blot W, Shy CM, Pickle LW, Toledo A, Fraumeni JF. Snuff dipping and oral cancer among women in the southern United States. New Eng J Med 1981;304:749-95.

39. Winn DM. Smokeless tobacco: the epidemiological evidence. CA Cancer J Clin 1988;38:236-43.

40. U.S. Department of Health and Human Services. The health consequences of using smokeless tobacco: a report of the advisory committee to the Surgeon General. NIH Publication No. 86-2874. Bethesda, MD: Public Health Service, National Institutes of Health, 1986.

41. McCarten B. Smokeless tobacco: the Irish and EU experience. Oral Dis 1998;4:56-7.

42. Hatsukami D, Severson H. Oral spit tobacco: addiction, prevention and treatment. Nicotine Tob Res Mar 1999;1(1):21-44. 
43. Grady D, Greene J, Daniels TE, et al. Oral mucosal lesions found in smokeless tobacco users. J Am Dent Assoc 1990;121:117-23.

44. Sterling TD, Rosenbaum WL, Weinkam JJ. Analysis of the relationship between smokeless tobacco and cancer based on data from the national mortality followback survey. J Clin Epidemiol 1992;42:223-31.

45. Bouquot JE, Meckstroth RL. Oral cancer in a tobaccochewing US population - no apparent increased incidence or mortality. Oral Surg Oral Med Oral Pathol Oral Radiol Endod 1998;86:697-706.

46. Schildt E-B, Eriksson M, Hardell L, Magnuson A. Oral infections and dental factors in relation to oral cancer: a Swedish case-control study. Eur J Cancer Prev 1998;6:201-6.

47. Rodu B. For smokers only: how smokeless tobacco can save your life. New York: Sulzberger \& Graham, 1995.

48. Rodu B, Cole P. Nicotine maintenance for inveterate smokers. Technology 1999;6:17-21.

49. Huhtasaari F, Asplund K, Lundberg V, Stegmyr B, Wester PO. Tobacco and myocardial infarction: is snuff less dangerous than cigarettes? Br Med J 1992;305:1252-6.

50. Bolinder G, Alfresson L, Englund A, de Faire U. Smokeless tobacco use and increased cardiovascular mortality. Am J Public Health 1994;84:399-404.

51. Persson G, Hellers G, Ahlbom A. Use of moist snuff and inflammatory bowel disease. Int $\mathrm{J}$ Epidemiol 1993;22:1101-3.

52. Axell TE. Oral mucosal changes related to smokeless tobacco usage: research findings in Scandinavia. Eur J Cancer Oral Oncol 1993;29B:299-302.

53. Axell TE. Smokeless tobacco and oral health: the Swedish experience. Oral Dis 1998;4:55-6.

54. International Agency for Research on Cancer. Tobacco smoking. IARC Monogr Eval Carcinog Risk Chem Hum 38. Lyon: IARC, 1986.

55. Wynder EL, Mushinski MH, Spivah JC. Tobacco and alcohol consumption in relation to the development of multiple primary cancers. Cancer 1977;40:1872-8.

56. Mashberg A, Meyers H. Anatomical site and size of 222 early asymptomatic oral squamous cell carcinomas: a continuing prospective study of oral cancer II. Cancer 1976;37:2149-57.

57. Jovanovic A, Schulten EAJM, Kostense PJ, Snow GB, van der Waal I. Tobacco and alcohol related to the anatomic site of oral squamous cell carcinoma. J Oral Path Med 1993;22:459-62.

58. Bofetta P, Mashberg A, Winkelmann R, et al. Carcinogenic effect of tobacco smoking and alcohol drinking on anatomic sites of the oral cavity and oropharynx. Int J Cancer 1992;52:530-3.

59. Hecht SS, Carmella SG, Murphy SE, Foiles PG, Chung FL. Carcinogen biomarkers relating to smoking and upper aerodigestive tract cancer. J Cell Biochem 1993;Supp 117F:27.

60. Hoffmann D, Hecht SS. Nicotine-derived N-nitrosamines and tobacco-related cancer: current status and future directions. Cancer Res 1985;45:935-44.

61. Lafuente A, Maristany M, Arias C, et al. Glutathione and glutathione S-transferases in human squamous cell carcinomas of the larynx and GSTM1-dependent risk. Anticancer Res 1998;18:107-11.
62. Firth NA. Marijuana use and oral cancer: a review. Oral Oncol 1997;6:398-401.

63. Darling MR, Arendorf TM. Effects of cannabis smoking on oral soft tissues. Community Dent Oral Epidemiol 1993;21:78-81.

64. International Agency for Research on Cancer. Alcohol drinking. IARC Monogr Eval Carcinog Risks Hum 40. Lyon: IARC, 1988.

65. Kato I, Nomura AM. Alcohol in the aetiology of upper aero-digestive tract cancer. Eur J Cancer Oral Oncol 1994;30B:75-81.

66. Hindle I. The epidemiology of oral cancer in England and Wales, 1901-1991. University of London, Ph.D. Thesis, 1997.

67. Bundgaard T, Wildt J, Frydenberg M, Elbrond O, Nielson JE. Case-control study of squamous cell cancer of the oral cavity in Denmark. Cancer Causes Control 1995;6:5767.

68. Blot WJ, McLaughlin JK, Winn DM, et al. Smoking and drinking in relation to oral and pharyngeal cancer. Cancer Res 1988;48:3282-7.

69. Andre K, Schraub S, Mercier M, Bontemps P. Role of alcohol and tobacco in the aetiology of head and neck cancer: a case-control study in the Doubs region of France. Eur J Cancer Oral Oncol 1995;31B:301-9.

70. Zheng T, Boyle P, Hu HF, et al. Tobacco smoking, alcohol and risk of oral cancer: a case-control study in Beijing, People's Republic of China. Cancer Causes Control 1990a; $1: 173-9$.

71. Boyle P, Macfarlane GJ, Blot WJ, et al. School of Oncology advisory report to the European Commision for the Europe Against Cancer Programme: oral carcinogenesis in Europe. Eur J Cancer Oral Oncol 1995;31B:75-85.

72. Brugere J, Guenel P, Leclerc A, Rodrigues J. Differential effects of tobacco and alcohol in cancer of the larynx, pharynx and mouth. Cancer 1986;57:391-5.

73. La Vecchia C, Tavani A. Fruit and vegetables and human cancer. Eur J Cancer Prev 1998;7:3-8.

74. Harris C, Warnakulasuriya KAAS, Gelbier S, Johnson NW, Peters TJ. Oral and dental health in alcohol misusing patients. Alcohol Clin Exp Res 1997;21:1707-9.

75. Winn DM, Blot WJ, McLaughlin JK, et al. Mouthwash use and oral conditions in the risk of oral and pharyngeal cancer. Cancer Res 1991;51:3044-7.

76. Elmore JG, Horwitz RI. Oral cancer and mouthwash use: evaluation of the epidemiologic evidence. Otolaryngol Head Neck Surg 1995;113:153-261.

77. Shapiro S, Castellana JV, Sprafka JM. Alcohol-containing mouthwashes and oropharyngeal cancer: a spurious association due to underascertainment of confounders? Am J Epidemiol 1996;144:1091-5.

78. Rich AM, Radden BG. Squamous cell carcinoma of the oral mucosa: a review of 244 cases in Australia. J Oral Pathol 1984;13:459-71.

79. Hodge KM, Flynn MB, Drury T. Squamous cell carcinoma of the upper aerodigestive tract in nonusers of tobacco. Cancer 1985;55:1232-5.

80. Ng SKC, Kabat GC, Wynder EL. Oral cavity cancer in non-users of tobacco. J Nat Cancer Inst 1993;85:743-5. 
81. Woods KV, Shilitoe EJ, Spitz MR, Storthz K. Analysis of human papillomavrius DNA in oral squamous cell carcinomas. J Oral Pathol Med 1993;22:101-8.

82. Park NH, Min BM, Li SL, Haung MZ, Cherrick HM, Doniger J. Immortilisation of normal human oral keratinocytes with type 16 human papillomavirus. Carcinogenesis 1991;12:1627-31.

83. Sexton CJ, Proby CM, Banks L, et al. Characterisation of the factors involved in human papilloma virus type 16-mediated immortalisation of oral keratinocytes. J Gen Virol 1993;74:755-61.

84. Shin K-H, Tannyhill RJ, Liu X, Park NH. Oncogenic transformation of HPV-immortalised human oral keratinocytes is associated with genetic instability of cells. Oncogene 1996;12:1089-96.

85. Penhallow J, Steingrimsdottir H, Elamin F, et al. p53 alterations and HPV infections are common in oral SCC: p53 gene mutations correlate with the absence of HPV 16-E6 DNA. Int J Oncol 1998;12:59-68.

86. Riethdorf S, Friedrich RE, Ostwald C, et al. p53 mutations and HPV infection in primary head and neck squamous cell carcinoma do not correlate with overall survival: a long term follow up study. J Oral Pathol Med 1997;26:315-21.

87. Miller CS, White DK. Human papillomavirus expression in oral mucosa, premalignant conditions, and squamous cell carcinoma: a retrospective review of the literature. Oral Surg Oral Med Oral Path Oral Radiol Endod 1996;82:57-68.

88. Sugerman PB, Shilitoe EJ. The high risk human papilloma viruses and oral cancer: evidence for and against a causal relationship. Oral Dis 1997;3:130-47.

89. Larsson PA, Johansson SL, Vahlne A, Hirsch JM. Snuff tumorigenesis: effects of long term snuff administration after initiation with 4-nitroquinoline $\mathrm{N}$-oxide and herpes simplex virus type 1. J Oral Pathol Med 1989;18:187-92.

90. Park K, Cherrick H, Min B-M, Park NH. Active HSV-1 immunisation prevents the co-carcinogenic activity of HSV-1 in the oral cavity of hamsters. Oral Surg Oral Pathol Oral Med 1990;70:186-91.

91. Larsson PA, Edstrom S, Westin T, Nordkrist A, Hirsch JM, Vahlne A. Reactivity against herpes simplex virus in patients with head and neck cancer. Int J Cancer 1991;49:14-8.

92. Rindum JL, Stenderup A, Holmstrup P. Identification of candida albicans types related to healthy and pathological oral mucosa. J Oral Pathol Med 1994;23:406-12.

93. Arendorf TM, Walker DM. Tobacco smoking and denture wearing as local aetiological factors in median rhomboid glossitis. Int J Oral Surg 1994;13:511-5.

94. Galai N, Park LP, Wesch J, Visscher B, Riddler S, Margolick JB. Effect of smoking on the clinical progres- sion of HIV-1 infection. J Acquir Immune Defic Synd Hum Retrovirol 1997;14:451-8.

95. Krogh P, Hald B, Holmstrup P. Possible mycological aetiology of oral mucosal carcinoma: catalytic potential of infecting Candida albicans and other yeasts in the production of N-nitrosobenzylmethylamine. Carcinogenesis 1987;8:1543-8.

96. Ranasinghe AW, Johnson NW, Scragg MA, Williams RA. Iron deficiency reduces cytochrome concentrations of mitochondria isolated from hamster cheek epithelium. J Oral Pathol Med 1989;18:582-5.

97. Prime SS, MacDonald DG, Rennie JS. The effect of iron deficiency on experimental carcinogenesis in the rat. $\mathrm{Br}$ J Cancer 1983;47:413-8.

98. La Vecchia C, Tavani A, Franceschi S, Levi F, Corragao G, Negri E. Epidemiology and prevention of oral cancer. Oral Oncol 1997;33:302-12.

99. Block G, Patterson B, Subar A. Fruit, vegetables and cancer prevention: a review of the epidemiological evidence. Nutr Cancer 1992;18:1-29.

100. Potter JD, Steinmetz K. Vegetables, fruit and phytoestrogens as preventive agents. Lyon: IARC Sci Publ 139, 1996:61-90.

101. Winn DM. Diet and nutrition in the aetiology of oral cancer. Am J Clin Nutr 1995;61:437S-45S.

102. McLaughlin JK, Gridley G, Block G, Winn DM, PrestonMartin S, Schoenberg JB. Dietary factors in oral and pharyngeal cancer. J Nat Cancer Inst 1988;80:1237-43.

103. Franceschi S, Barzan L, Talamini R. Screening for cancer of the head and neck: if not now, when? Oral Oncol 1997;33:313-6.

104. Franco EL, Kowalski LP, Oliveira BV, et al. Risk factors for oral cancer in Brazil: a case-control study. Int J Cancer Jun 1989 15;43(6):992-1000.

105. Zheng T, Boyle P, Willett WC, et al. A case-control study of oral cancer in Beijing, People's Republic of China. Associations with nutrient intakes, foods and food groups. Eur J Cancer Oral Oncol 1993;29B:45-55.

106. Nomura AM, Ziegler RG, Stemmerman GN, Chyou PH, Craft NE. Serum micronutrients and upper aerodigestive tract cancer. Cancer Epidemiol Biomarkers Prev 1997;6:407-12.

107. Riboli E, Kaaks R, Esteve J. Nutrition and laryngeal cancer. Cancer Causes Control 1990;1:147-56.

108. Velly AM, Franco EEL, Schlecht N, et al. Relationship between dental factors and risk of upper aerodigestive tract cancer. Oral Oncol 1998;34:284-91.

109. Lockhart PB, Norris CM, Pulliam C. Dental factors in the genesis of squamous carcinoma of the oral cavity. Oral Oncol 1998;34:133-9. 